DOI: 10.20472/IAC.2018.036.036

\title{
LEILA PAZARGADI
}

Nevada State College, United States

\section{SUMMER BRIDGE PROGRAMS: CHAMPIONING INCLUSION AND DECREASING SOCIO-ECONOMIC GAPS}

\begin{abstract}
:
This paper explores the ways in which Summer Bridge Programs champion equity and inclusion amongst underrepresented and first-generation college students. By supporting these students with course instruction, tutoring, and peer mentorship during the summer term, bridge programs aim to create an inclusive approach to education and narrow achievement gaps, especially along socio-economic lines. Additionally, instructors serve as peer educators, playing a pivotal role in advocating equity and inclusion for all students who enter university. University Summer Bridge Programs aim to narrow the achievement gap between the performances of college-going students and first-generation college students. Two such programs at the University of California, Los Angeles and Nevada State College are the focus of this talk. Each program employed the narrative approach of asking students, peer educators, and teachers to exchange their life stories as a way of: raising awareness about identity capital, encouraging identification with others, and inspiring transformation through self actualization. This approach allows students, peer educators, and teachers to display forms of empathetic witnessing, enabling students to explore one another's layered identity. This talk not only discusses the needed academic organization, institutional support, didactics, and pedagogical strategies behind the bridge model, but it also includes findings and outcomes about first-generation students' perceived academic pathways. Ultimately, bridge programs demonstrate how a community of educators, alumni, and peer mentors pivotally create an inclusive environment that paradigmatically provides access and stimulates success in education. These programs support students in the discovery of both their voice and identity capital in order to encourage them to assert their agency.
\end{abstract}

\section{Keywords:}

inclusion, diversity, underrepresented students, first-generation college student, summer bridge programs

JEL Classification: $124,123,129$ 